Kroneman, M., Oort, M. van, Groenewegen, P., Jong, D. de

Variation in day surgery among Dutch hospitals: the development of a

theoretical model to explain variations.

Ambulatory Surgery: 10, 2003, nr. 2, p. 73-79

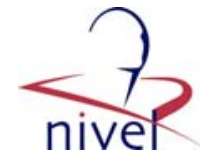

\begin{tabular}{|l|l|}
\hline Postprint Version & 1.0 \\
\hline Journal website & http://dx.doi.org \\
\hline Pubmed link & \\
\hline DOI & $10.1016 /$ S0966-6532(02)00043-4 \\
\hline
\end{tabular}

* Corresponding author. Tel.: -/31-30-272-9640/700; fax: -/31-30-272-9729.

E-mail address: m.kroneman@nivel.nl (M. Kroneman).

\title{
Variation in day surgery among Dutch hospitals: The development of a theoretical model to explain variations
}

\author{
Madelon Kroneman ${ }^{\text {A, }}$, Maureen VAN OORT ${ }^{\text {A }}$, Peter GroeneWegen ${ }^{\text {A }}$, Dick DE Jong ${ }^{\text {B }}$ \\ a NIVEL, Netherlands Institute for Health Services Research, P.O. Box 1568, 3500 BN Utrecht, The \\ Netherlands \\ bVU-medical centre, Vrije Universiteit Amsterdam, P.O. Box 7057, 1007 MB Amsterdam, The \\ Netherlands
}

\begin{abstract}
The aim of this paper is providing a first step in explaining variations in day surgery rates among Dutch hospitals. A theoretical model was set up to explain variations based on diffusion theory and environmental characteristics. We tried to test our model by means of routinely collected data from administrative databases. The S-shaped curve of diffusion could be shown combining data on laparoscopic cholecystectomies (early phase of adoption), cataract surgery (middle phase) and curettage and dilatation (late phase of adoption). The theoretical model was translated into a regression model for the latter two procedures. The routinely collected data appeared not adequate to test our hypotheses. The data were available only at hospital level. Probably more detailed data on physician partnerships and hospital circumstances are needed to adequately test our hypotheses.
\end{abstract}

\section{INTRODUCTION}

Ambulatory surgery in its present form started in the United States of America in the early 1960s [1]. Ambulatory surgery (also called day surgery) is clinical admission for a surgical procedure, with discharge of the patient on the same working day. Especially in the last decade the number of admissions for day surgery has increased greatly. This increase was facilitated by innovations in surgical and anaesthetic techniques. The implementation of new surgical procedures, for example minimal invasive surgery, and new short-acting anaesthetics with minimal cardiovascular side effects made early discharge possible. However, there is quite some variation in the use of day surgery, at least among countries [2].

Day surgery can be seen as a new technology, and therefore, the theory of diffusion of knowledge and technologies may be applied to this field. Beside acceptance of new technologies, variation may stem from the environment in which day surgery takes place, for instance the hospital's day surgery facilities, the number of beds for in-patient admission, waiting lists for surgical treatments and financial arrangements. We can reasonably expect that insurers will try to promote more cost-effective procedures. Cost-effective means an intervention that gives good benefit in relation to costs compared with other procedures. Besides this, the use of these techniques may have been stimulated by inpatient bed reductions [3].

The diffusion of technologies, together with the environmental characteristics, takes a central place in this paper. Some hospitals or specialists adopt new technologies necessary for day surgery earlier than others. The central questions of this paper are: 
Kroneman, M., Oort, M. van, Groenewegen, P., Jong, D. de

Variation in day surgery among Dutch hospitals: the development of a

theoretical model to explain variations.

Ambulatory Surgery: 10, 2003, nr. 2, p. 73-79

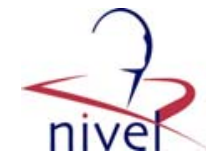

1. What is the extent of variation in day surgery in the Netherlands?

2. To what extent can this variation be explained from environmental circumstances and diffusion processes by analyzing data from an existing data-set?

\subsection{Diffusion}

Diffusion can be defined as the process by which an innovation is communicated through certain channels over time among the members of a social system [4]. The development of medical innovations does not mean that innovations actually will be put into use. Many innovations require a lengthy period, often of some years, from the time they become available to the time when they are widely adopted [4]. Prior to the adoption of an innovation, hospitals and physicians will have to be acquainted with the innovation, and further more, they have to be convinced of the advantages and disadvantages of it. Following acquaintance with the innovation, the decision will be made whether to adopt or reject the innovation. Not every hospital or physician wants to adopt new treatment methods from the instant they are invented.

Adopters can be divided in primary adopters and secondary adopters. Primary adopters are those persons that actually have to use the interventions. In this case these are the medical specialists. Secondary adopters are those who facilitate or restrict the primary adopter's behavior. In this case these are the hospital management and patients. Patients can only be treated by day surgery when they give their consent for this type of treatment. On the side of the hospital and its management day surgery is restricted or facilitated by the hospital's willingness to invest in the necessary infrastructure. Both primary and secondary adopters are assumed to behave rationally and be goal oriented. Their behavior is aimed at utility maximization given their preferences and constraints (according to rational choice theory, elaborated by Coleman [5] and Lindenberg [6]). The assumption of goal oriented behavior is important in explaining socially patterned phenomena, because it enables us to account for reasoned changes in behavior. We assume that the main assignment of both physician and hospital is to improve patients' health. However, in choice situations with equivalent or uncertain outcomes, there is room for considerations other than medical interest.

We suppose that medical specialists aim at improving their patients' health, keep an eye on their own financial interests and workload, and try to gain prestige with their colleagues. For patients we assume that they want their health problem solved, their anxiety reduced, and to keep an eye at their broader social and financial wellbeing. Hospitals, personified by their management, are supposed to strive to survive as an organization by keeping the organization financially healthy and being attractive to patients and personnel [8].

Rogers [4] distinguishes three types of adopters in three different stages. The first adopters are called the innovators. When the diffusion progresses, the early majority adopts the new technology. Finally, in the last stage, the last group will accept the new technology. This group is called the laggards. The question now is how the adoption of day surgery contributes to the goal attainment by each of these groups of actors. It could be argued that the early adoption of day surgery (by the innovators) depends on the variation between the individual ambition of medical specialists to innovate, which may contribute to variation among primary adopters. However, without institutional support from the hospital, innovations like day surgery will not survive, especially when institutional investments (like special waiting rooms, wards or operatis theatres) are needed. Adoption of day surgery at this stage will acquire the character of strategic choices by medical specialists and hospital management. Strategic choices, by adopting new technologies, are pro-active, look at long term survival and less at short term gain. It is expected that in the early phases of diffusion, immaterial influences will be more important than in the later phases. The adoption of day surgery in the later phases (early majority and laggards) of the diffusion process is probably more driven by regulative forces (such as reimbursement rules of third party payers), normative forces (if many people in many other places can be treated in day surgery, this becomes the normal expectation), and mimetic forces (specialists and hospitals doing what most others do) $[7,9]$. The implication might be that in the later phases of diffusion of day surgery material influences such as funding, payment and insurance are more important.

\subsection{Hypotheses}

Table 1 specifies a number of structural conditions and hypotheses about the relative attractiveness of day surgery compared with in-patient treatment. 
Kroneman, M., Oort, M. van, Groenewegen, P., Jong, D. de

Variation in day surgery among Dutch hospitals: the development of a

theoretical model to explain variations.

Ambulatory Surgery: 10, 2003, nr. 2, p. 73-79

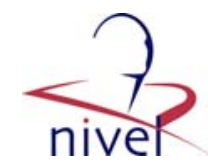

\section{[ TABLE 1 ]}

The attractiveness of day surgery depends on conditions at the health system level (payment, funding and insurance systems) and differs for hospital, specialist and patient. For each phase of the adoption process, the different conditions may differ in importance.

\section{DATA AND METHODS}

\subsection{Data}

This study is based on two data-sets.

The first data-set contains national rates of day surgery of the years 1992-1999 for different procedures. With these data we illustrate the diffusion of admissions for day surgery in the course of time. We choose three interventions, that are in different phases of the diffusion process. The percentage of day surgery in which the intervention has been carried out determined the categorizing in the different stages of diffusion. These interventions are: cholecystectomy (adopted only by innovators), cataract surgery (adopted by the early majority) and curettage and dilatation of the uterus (almost all have adopted the intervention, besides laggards).

The second data-set is a cross-section of all Dutch hospitals in the year 1995. From each hospital data were available the number of places for in-patient admission, the number and the rates of day surgery for a number of interventions, the degree of urbanization of the hospital market area, the number of hospitals in the same area, the percentage of senior citizens (65 years and older) and the number of general practioners (GPs) per 1000 inhabitants in the health area around the hospital.

Both data-sets contain data that are routinely collected in the Nationwide Medical Registration Program (Landelijke Medische Registratie (LMR)) by Prismant [10].

\subsection{Illustrating a diffusion curve}

Diffusion of innovations is a dynamic process and we tried to capture some of the dynamics of the process by comparing different interventions that are in a different phase of the diffusion process. Assuming that the diffusion of day surgery as an innovation in medical care shows the characteristic pattern of many innovations, one might expect that the adoption of different procedures in day surgery show the same cumulative pattern: the S-curve or logistic curve. Therefore, a Scurve was fitted through the consequent phases of the three procedures, based on the data of all three procedures together.

\subsection{Operationalizing the hypotheses}

For each actor, the hypotheses were operationalized, if possible, using the routinely available data. We were not able to test the hypotheses concerning the specialists conditions, since we either did not have suitable data (number of specialists in partnership per hospital, attitudes towards workload of day surgery compared with in-patient care) or the data did not vary within our research area (remuneration of day surgery).

From the hospital data, we used the size of hospitals in terms of the number of beds as a proxy for the benefit of applying new technologies. Larger hospitals are assumed to have larger budgets available for technological investments. Besides, larger hospitals see more patients and may benefit of economies of scale. Demand pressure on a hospital is represented by the number of in-patient beds per 1000 inhabitants and by the proportion of elderly (65 years or older) in the hospital market area. The idea is that elderly have a larger chance of (complicated) health problems and thus give a larger demand pressure on in-patient beds. A high proportion of elderly will, therefore, lead to higher day surgery rates, because younger, relatively healthier patients will be treated in day surgery in order to free in-patient capacity for the elderly. Another source of pressure on available beds within a hospital, is bed reduction, expressed in the proportional bed reduction per hospital within a period of 5 years (1990-1995). No data were available about the existence of special wards for day surgery in 1995. The competition among hospitals is expressed by the number of hospitals in the hospital market area.

The patient variables were operatonalized as follows. In the Netherlands, there is no co-payment for day surgery nor for in-patient care, so the hypothesis concerning the insurance coverage could not be 
Kroneman, M., Oort, M. van, Groenewegen, P., Jong, D. de

Variation in day surgery among Dutch hospitals: the development of a

theoretical model to explain variations.

Ambulatory Surgery: 10, 2003, nr. 2, p. 73-79

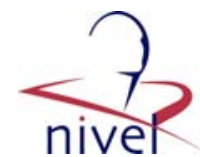

tested. The degree in which patients are covered by after care was estimated by the number of GPs per 1000 inhabitants.

\subsection{Regression model}

Summarising, we draw up the following regression equation:

\begin{tabular}{|c|c|}
\hline Rate of day surgery $=$ & f (hospital size, beds, GP’s, elderly, competition) \\
\hline where, hospital size $=$ & number of in-patient beds in the hospital \\
\hline beds $=$ & $\begin{array}{l}\text { number of beds per } 1000 \text { inhabitants in the hospital market area bed } \\
\text { reduction-this is a dummy variable. The value } 1 \text { indicates a bed reduction in } \\
\text { the period } 1990 \text { - } 1995 \text { per hospital, the value } 0 \text { indicates no reduction }\end{array}$ \\
\hline Gps $=$ & number of GP’s per 1000 inhabitants elderly-percentage \\
\hline elderly = & people (65-) in a health area ${ }^{1}$ \\
\hline Competition $=$ & number of hospitals in a health area². \\
\hline
\end{tabular}

Two regression models were set up. One for cataract surgery and one for curettage and dilatations of the uterus. For cholecystectomy the percentage of interventions carried out in day surgery was too small to obtain reliable results. We assume that for cataract surgery the effects of the independent variables will be different from those for curettage and dilatation of the uterus. Cataract surgery was in 1995 less commonly carried out in day surgery compared with curettage and dilatation of the uterus. Therefore, surgeons that perform cataract surgery in day surgery, and hospitals that provide the facilities, can be classified as early majority in terms of Rogers diffusion theory. The surgeons or hospitals that still do not carry out curettage and dilatations of the uterus in day surgery may be characterized as laggards in this case.

\section{RESULTS}

In Fig. 1 we show that the distinctive interventions indeed can be projected on a S-shaped curve.

\section{[ FIGURE 1 ]}

Laparoscopic cholecystectomy belongs to the group of interventions which are seldom undertaken in a day setting in The Netherlands at present, and thus represents a technique in the phase of adaptation by innovators. An increase is expected since in the USA ambulatory laparoscopic cholecystectomy showed a strong expansion. Lau and Brooks [11] showed an increase from $0.6 \%$ in 1993 to $48 \%$ in 1997 in a major teaching hospital. Also in Canada, laparoscopic cholecystectomy rates increased strongly in 1 year by about 18\%, resulting in a 35.6\% rate in 1997-1998 [12]. In the Netherlands in 1992 the percentage was $0 \%$ and in 2000 the percentage was just below $2 \%$. The second intervention, cataract surgery, was in 1995 adopted by early adopters. It is placed in the middle section of the Scurve in Fig. 1. Curettage and dilatation of the uterus can be categorized in the phase of adoption by laggards since the majority of these interventions are executed in day surgery. The results show that there is variation among interventions in the degree in which they are carried out in day surgery.

To investigate the influence of circumstantial characteristics on day surgery rates and whether the influence of these characteristics differs by phase of diffusion, we carried out regression analyses. The results of the regression equations are shown in Table 2.

\footnotetext{
${ }^{1} \mathrm{~A}$ health area is an administrative region based on the hospital planning act (WZV-regio).

2 A health area is an administrative region based on the hospital planning act (WZV-regio).
} 


\section{[ TABLE 2 ]}

The results show that none of the expected relationships could be demonstrated. None of the estimates are significant $(P<0.05)$.

\section{CONCLUSION AND DISCUSSION}

In this study we focussed on the diffusion of day surgery and the conditions that influence this diffusion. Diffusion is the process by which an innovation is communicated through certain channels over time among the members of a social system [4]. We argued that the adoption of day surgery in the early phases of diffusion acquires the character of strategic choices by medical specialists and hospital management. In the last phases material influences such as funding, payment and insurance type may become more important in adopting the new procedures.

Our first research question concerned the extent of variation in day surgery in the Netherlands. We conclude that the total variation of day surgery differs among different interventions. Through the rates of day surgery for laparoscopic cholecystectomy, cataract surgery and curettage and dilatation of the uterus during the years 1992 till 1999, an illustrative S-curve can be drawn. Physicians that provide laparoscopic cholecystectomy in a day surgery setting can be classified as innovators. The executers of cataract surgery in day surgery admission can be classified as early adopters. The surgeons who did not execute curettage and dilatation of the uterus in day surgery admission in the year 1995 may be characterized as laggards. For curettage and dilatations of the uterus the upper limit of what is medically possible in day surgery could well be reached. The medically based upper limit might differ according to the procedure studied and could for instance be lower for cholecystectomy.

Besides variation among interventions, there is variation among hospitals in the rate of day surgery within one intervention. To explain this variation (second research question) a set of hypotheses was set up about the role of different actors in the adoption of day surgery (see Table 1).The findings, however, do not confirm our theory. We think this is due to the abstract level of the variables we used to operationalize our hypotheses. We have tried to make use of readily available, nation wide routinely collected data. Since these secondary data were collected for other purposes than our research, this brings unavoidable second best choices of variables. For a test of the hypotheses, more specific data, especially data on physician and patient characteristics are necessary.

Probably, the variation in day surgery can be explained by variables on the level of the specialist working in the hospital and on the patient level. Earlier in this paper we motivated the role of the specialist in the choice for carrying out day surgery, like age of the physician (young physicians tend to adopt innovations earlier than older physicians) and number of specialists in the specialist partnership. Furthermore, patients' characteristics, such as age, possibilities for home care, insurance and preference for day surgery or hospital admission can have an influence on the rate of day surgery. But for none of these characteristics we have data.

This study has taken a step in the direction of studying the variation in day surgery by defining the relationship between day surgery and hospital size, number of beds, bed reduction and number of GP's per 1000 inhabitants in the hospital market area, percentage of elderly and the number of hospitals in the hospital market area. It is possible of course that other variables explain more of the extent of the variation.

It is worth while to look at how you can use routinely collected data for answering new research questions. You can save time and money by using existing data instead of collecting new data. Moreover you experience what sort of data are important for answering you research questions. In spite of the limitations our theoretical model gives more insight in how variation in day surgery can be explained. The approach outlined in this study should be replicated on the basis of primary data on the level of the patient and the specialists. Additionally it can be an argument to study the interaction between variables on different levels. 
Kroneman, M., Oort, M. van, Groenewegen, P., Jong, D. de

Variation in day surgery among Dutch hospitals: the development of a

theoretical model to explain variations.

Ambulatory Surgery: 10, 2003, nr. 2, p. 73-79

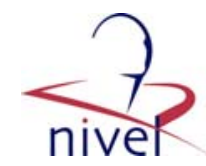

\section{TABLES}

Table 1

Adopters of day surgery in relation with conditions and goals

\begin{tabular}{|c|c|c|c|c|}
\hline $\begin{array}{l}\text { Adopters of } \\
\text { day surgery }\end{array}$ & Goals & Structural conditions & Attractiveness of day surgery is higher if & Operationalization $^{\mathrm{b}}$ \\
\hline \multirow[t]{4}{*}{ Specialists } & $\begin{array}{l}\text { Health of pa- } \\
\text { tients }\end{array}$ & $\begin{array}{l}\text { Employment situation/ } \\
\text { payment system }\end{array}$ & Day surgery is better remunerated & - \\
\hline & $\begin{array}{l}\text { Income/work- } \\
\text { load }\end{array}$ & Number of colleagues & $\begin{array}{l}\text { Day surgery is associated with lower } \\
\text { workload }\end{array}$ & - \\
\hline & Prestige & & $\begin{array}{l}\text { The number of specialists in the group is } \\
\text { larger }\end{array}$ & - \\
\hline & & & Age of specialist is lower & - \\
\hline \multirow[t]{6}{*}{ Hospitals } & $\begin{array}{l}\text { Financially } \\
\text { healthy }\end{array}$ & $\begin{array}{l}\text { Funding and budgeting } \\
\text { system }\end{array}$ & $\begin{array}{l}\text { Budget available for innovations/new } \\
\text { technologies }\end{array}$ & Hospital size (beds) \\
\hline & $\begin{array}{l}\text { Attractive to } \\
\text { patients }\end{array}$ & Market situations & $\begin{array}{l}\text { Hospitals are funded by global budgets or } \\
\text { DRGs }^{\mathrm{a}}\end{array}$ & - \\
\hline & $\begin{array}{l}\text { Attractive to } \\
\text { personnel }\end{array}$ & $\begin{array}{l}\text { Availability of clinical and } \\
\text { day surgery facilities }\end{array}$ & Demand pressure on hospital beds & $65+$ in market area \\
\hline & & & $\begin{array}{l}\text { The number of clinical beds is smaller } \\
\text { and/or has decreased more in the preced- } \\
\text { ing years }\end{array}$ & $\begin{array}{l}\text { Beds per } 1000 \text { inhabitants in market } \\
\text { area and decrease in beds in } 5 \text { years }\end{array}$ \\
\hline & & & Special day surgery wards are available & - \\
\hline & & & $\begin{array}{l}\text { More competing hospitals are active in } \\
\text { the area }\end{array}$ & Number of hospitals in market area \\
\hline \multirow[t]{4}{*}{ Patients } & Health & $\begin{array}{l}\text { Age, probability of com- } \\
\text { plications }\end{array}$ & Patients are in good physical condition & - \\
\hline & Costs & Insurance status & $\begin{array}{l}\text { Their insurance coverage for hospital days } \\
\text { is worse (e.g. bed day co-payments) }\end{array}$ & - \\
\hline & $\begin{array}{l}\text { Burden on social } \\
\text { network }\end{array}$ & $\begin{array}{l}\text { Availability of (in)formal } \\
\text { cares }\end{array}$ & Patients are covered by formal home care & $\begin{array}{l}\text { Number of GP's per } 1000 \text { inhabitants in } \\
\text { market area }\end{array}$ \\
\hline & & & $\begin{array}{l}\text { Patients are covered by informal home } \\
\text { care }\end{array}$ & - \\
\hline
\end{tabular}

a Compared with per diem payment.

b -, No operationalization possible with the available data.

Laparoscopic Cholecystectomy

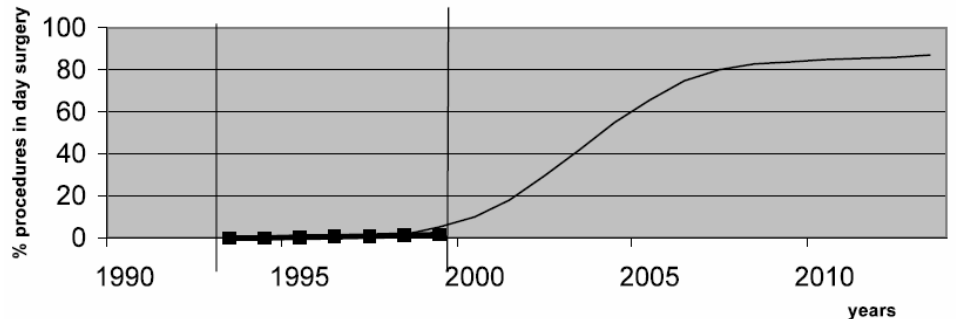

Cataract surgery

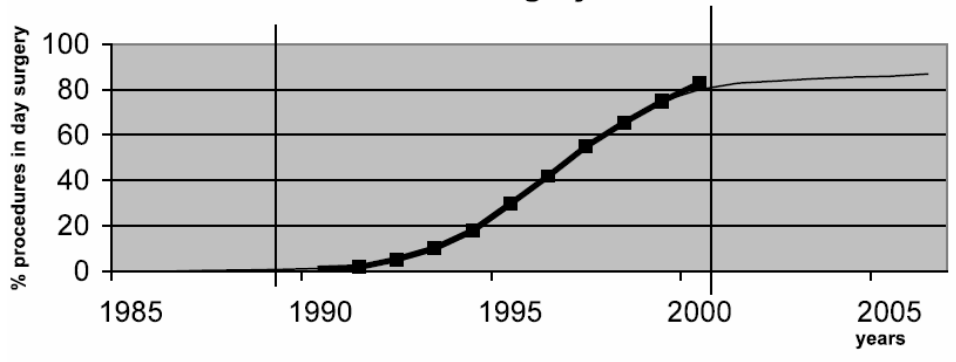

Curettage and Dilatation

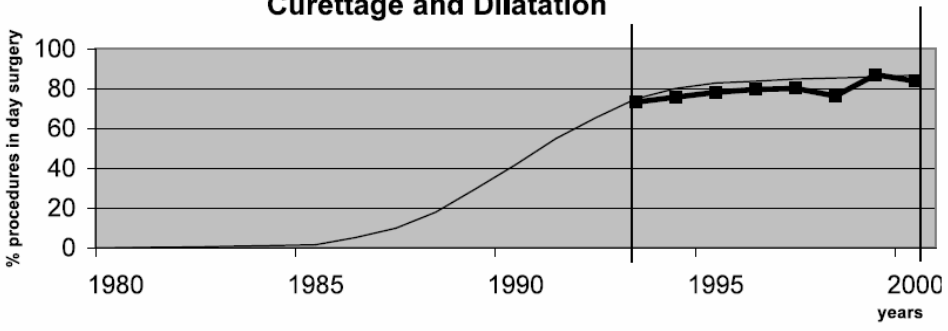

Fig. 1. The diffusion of day surgery in The Netherlands for selected procedures. 
Kroneman, M., Oort, M. van, Groenewegen, P., Jong, D. de

Variation in day surgery among Dutch hospitals: the development of a

theoretical model to explain variations.

Ambulatory Surgery: 10, 2003, nr. 2, p. 73-79

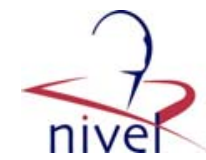

Table 2

Regression analyses to explain variation in day surgery $(n=106)$

\begin{tabular}{|c|c|c|c|c|}
\hline Dependent variables & Independent variables & $B$-coefficients & $t$-values & Significance \\
\hline \multirow{8}{*}{ Rate of day surgery for cataract surgery } & Hospital size & 0.02 & 1.39 & 0.17 \\
\hline & Beds & 1.33 & 0.26 & 0.78 \\
\hline & GPs & 99.97 & 0.75 & 0.46 \\
\hline & Elderly & 86.56 & 0.41 & 0.68 \\
\hline & Competition & -2.03 & -1.71 & 0.09 \\
\hline & Bed reduction & -12.58 & -1.83 & 0.07 \\
\hline & Constant & -19.77 & -0.29 & 0.77 \\
\hline & Adjusted $R^{2}$ & 0.02 & - & - \\
\hline \multirow[t]{8}{*}{ Rate of day surgery for curettage and dilatation } & Hospital size & -0.01 & -1.35 & 0.18 \\
\hline & Beds & 0.18 & 0.09 & 0.93 \\
\hline & GPs & -29.56 & -0.54 & 0.59 \\
\hline & Elderly & -9.50 & -0.11 & 0.91 \\
\hline & Competition & 0.34 & -0.69 & 0.49 \\
\hline & Bed reduction & 0.815 & 0.29 & 0.77 \\
\hline & Constant & 92.86 & 3.33 & 0.00 \\
\hline & Adjusted $R^{2}$ & 0.00 & - & - \\
\hline
\end{tabular}

\section{REFERENCES}

[1] Davis JE. The major ambulatory surgical center and how it is developed. Surgical Clinics of North America 1987;67(4):671-92.

[2] Kroneman MW. Healthcare systems and hospital bed use. Utrecht: NIVEL, 2001.

[3] Kroneman MW, Westert GP, Groenewegen PP, Delnoij DMJ. International variations in the availability and diffusion of alternatives to in-patient care in Europe: the case of day surgery. Ambulatory Surgery 2001;9:147-54.

[4] Rogers EM. Diffusion of innovations. London: Collier Macmillan Publishers, 1983.

[5] Coleman JS. Foundations of social theory. Cambridge, MA: The Belknap Press of Harvard University Press, 1990.

[6] Lindenberg SM. The new political economy: its potential and limitations for the social sciences in general and for sociology in particular. In: Sodeur W, editor. Ökonomische erklärungen sozialen verhaltens [economic explanations for social behaviour]. Duisburg: Verlag der sozialwissenschaftlichen Kooperative, 1983:1-68.

[7] Greer AL. Diffusion of innovation in health care organizations. International journal of technology assessment in health care 1985;1(3):669-80.

[8] Groenewegen PP. Het gedrag van hulpverleners en patiënten [the behaviour of health providers and patients]. Tijdschrift voor sociale gezondheidszorg 1996;74(2):4-9.

[9] Scott WR. Institutions and organizations. London: Sage Publications, 2001.

[10] Prismant, Landelijke Medische Registratie: Nationwide Medical Registration Program, Data-set

Day Surgery among Dutch Hospitals, Utrecht, 1995 [data-set].

[11] Lau H, Brooks DC. Transitions in laparoscopic cholecystectomy: the impact of ambulatroy surgery. Surgical Endoscopy 2002;16:323-6.

[12] de Lathouwer C, Poullier JP. How much ambulatory surgery in the world in 1997-1997 and trends. Ambulatory Surgery 2000;8:191 -210. 